\title{
Colistin Resistance Onset Strategies and Genomic Mosaicism in Clinical Acinetobacter baumannii Lineages
}

\author{
Viviana Cafiso ${ }^{1, *(\mathbb{D}}$, Stefano Stracquadanio ${ }^{1}{ }^{\mathbb{D}}$, Veronica Dovere ${ }^{2}$, Flavia Lo Verde ${ }^{1}$, Alessandra Zega ${ }^{1}$, \\ Giuseppe Pigola $^{1}$, Simona Barnini ${ }^{3}$, Emilia Ghelardi ${ }^{2} \mathbb{D}$ and Stefania Stefani ${ }^{1}$ (D) \\ 1 Department of Biomedical and Biotechnological Sciences, University of Catania, 95123 Catania, Italy; \\ s.stracquadanio@unict.it (S.S.); flavia.loverde@hotmail.it (F.L.V.); alessandra.zega@libero.it (A.Z.); \\ gpigola@gmail.com (G.P.); stefania.stefani@unict.it (S.S.) \\ 2 Department of Translational Research and New Technology in Medicine and Surgery, Azienda \\ Ospedaliero-Universitaria Pisana, University of Pisa, 56126 Pisa, Italy; veronicadovere@gmail.com (V.D.); \\ emilia.ghelardi@med.unipi.it (E.G.) \\ 3 Bacteriology Unit of Azienda Ospedaliero-Universitaria Pisana, 56126 Pisa, Italy; barninis@gmail.com \\ * Correspondence: v.cafiso@unict.it
}

check for updates

Citation: Cafiso, V.; Stracquadanio, S.; Dovere, V.; Lo Verde, F.; Zega, A.; Pigola, G.; Barnini, S.; Ghelardi, E.; Stefani, S. Colistin Resistance Onset Strategies and Genomic Mosaicism in Clinical Acinetobacter baumannii Lineages. Pathogens 2021, 10, 1516. https://doi.org/10.3390/ pathogens10111516

Academic Editor: Luisa De Martino

Received: 20 October 2021

Accepted: 18 November 2021

Published: 20 November 2021

Publisher's Note: MDPI stays neutral with regard to jurisdictional claims in published maps and institutional affiliations.

Copyright: (c) 2021 by the authors. Licensee MDPI, Basel, Switzerland. This article is an open access article distributed under the terms and conditions of the Creative Commons Attribution (CC BY) license (https:// creativecommons.org/licenses/by/ $4.0 /)$.

\begin{abstract}
The treatment of multidrug-resistant Gram-negative infections is based on colistin. As result, COL-resistance (COL-R) can develop and spread. In Acinetobacter baumannii, a crucial step is to understand COL-R onset and stability, still far to be elucidated. COL-R phenotypic stability, onset modalities, and phylogenomics were investigated in a clinical A. baumannii sample showing a $\mathrm{COL}$ resistant $\left(\mathrm{COL}^{\mathrm{R}}\right)$ phenotype at first isolation. COL-R was confirmed by Minimum-InhibitoryConcentrations as well as investigated by Resistance-Induction assays and Population-AnalysisProfiles (PAPs) to determine: (i) stability; (ii) inducibility; (iii) heteroresistance. Genomics was performed by Mi-Seq Whole-Genome-Sequencing, Phylogenesis, and Genomic Epidemiology by bioinformatics. $\mathrm{COL}^{\mathrm{R}}$ A. baumannii were subdivided as follows: (i) 3 A. baumannii with stable and high COL MICs defining the "homogeneous-resistant" onset phenotype; (ii) 6 A. baumannii with variable and lower COL MICs displaying a "COL-inducible" onset phenotype responsible for adaptive-resistance or a "subpopulation" onset phenotype responsible for COL-heteroresistance. COL-R stability and onset strategies were not uniquely linked to the amount of LPS and cell envelope charge. Phylogenomics categorized 3 lineages clustering stable and/or unstable COL-R phenotypes with increasing genomic complexity. Likewise, different nsSNP profiling in genes already associated with COL-R marked the stable and/or unstable COL-R phenotypes. Our investigation finds out that A. baumannii can range through unstable or stable $\mathrm{COL}^{\mathrm{R}}$ phenotypes emerging via different "onset strategies" within phylogenetic lineages displaying increasing genomic mosaicism.
\end{abstract}

Keywords: A. baumannii; colistin resistance stability; genomic mosaicism; phylogenetic lineages

\section{Introduction}

In the last twenty years, Acinetobacter baumannii has become a major threat not only as an important pathogen associated with nosocomial and community infections at various body sites, including the bloodstream, respiratory tract, urinary tract, surgical sites, and wounds [1], but also because it poses a huge challenge in clinical settings due to its intrinsic and acquired antimicrobial resistance. The development of multidrug resistance (MDR) in A. baumannii is due to genomic mutations, acquired antimicrobial resistance genes, or modifications in the expression of some genes [2]. Because of the significant increase in the isolation of carbapenem-resistant $A$. baumannii (CR-A. baumannii) and, until recently, the lack of active drugs against this microorganism, colistin (COL) has been used to treat CR-A. baumannii infections despite its nephrotoxicity, representing, in combination, a last-line therapy. Eventually and not unexpectedly, the emergence of colistin-resistant $\left(\mathrm{COL}^{\mathrm{R}}\right)$ A. baumannii was reported worldwide [3] and it is caused by mutations or altered 
expression of diverse genes—mainly $p m r$ and $l p x$ genes [4] as well as galU [5]—or the acquisition of the plasmidic gene $\mathrm{mcr}$ [6]. Nonetheless, colistin resistance (COL-R) is still low or variable across countries, while, as reported by Karokostantis (2020), the prevalence of COL heteroresistance seems to be more common $[3,7,8]$. Heteroresistance is usually defined as the presence of subpopulations with MIC values higher (variably defined as equal to or more than two- to eight-fold) than the MIC in the main population, is often associated with the previous use of the drug, and represents major trouble in clinical settings as resistant subpopulations can emerge during treatment, resulting in treatment failure. Colistin heteroresistance in A. baumannii is even more alarming as it was detected even in isolates without prior exposure to colistin, suggesting that it could be an inherent characteristic of this species [8,9]. Moreover, a concentration of antibiotic $>128 \mathrm{mg} / \mathrm{L}$ was shown to be necessary to prevent the onset of colistin heteroresistant $A$. baumannii mutants, as previously reported [10]; this is much higher than colistin serum concentrations (median $2.36 \mathrm{mg} / \mathrm{L}$ ) associated with approximately $50 \%$ toxicity rates [10]. Adding to the complexity in fully understanding the $\mathrm{COL}^{\mathrm{R}}$ A. baumannii threat, there are cases where COL minimum inhibitory concentration (MIC) values vary over time for the same A. baumannii strain, ranging from values lower than the susceptibility cut-off to higher values [11] even in the absence of heteroresistant subpopulations.

As already stated, different studies showed that COL heteroresistance in A. baumannii is common, but the real frequency rate is not determined [12], probably due to the absence of easy-to-perform tests, ranging from $18 \%$ to $100 \%$ of COL heteroresistant clinical strains. Furthermore, studies do not usually perform either resistance induction assays or MIC tests on strains cultured for different days $[13,14]$. These lack of analyses could lead to a misunderstanding in the detection of the COL heteroresistance, as it may result in underestimated or overestimated since the induction assays could promote the raise of $\mathrm{COL}^{\mathrm{R}}$ subpopulation, whereas culturing resistant strains for a long time could result in the loss of COL-R.

Although some studies have already investigated the presence of well-known mutations in the genes responsible for COL-R in resistant and heteroresistant $A$. baumannii strains [3,15-17], to the best of our knowledge no one has ever analyzed their whole genomes to group them based on their similarities and differences. Herein, we conducted a phenotypic and genomic characterization as well as investigated the phylogenetic relationship in A. baumannii samples displaying different levels of colistin resistance and heteroresistance, suggesting three different strategies that $A$. baumannii can use to become resistant.

\section{Results}

\subsection{COL MIC}

In 10 repeated MIC assays, the $1 \mathrm{R}, 2 \mathrm{R}$, and 3R strains showed a stable and high COL MIC of $128 \mathrm{mg} / \mathrm{L}$ defining the "homogeneous-resistant" onset phenotype, and hence FullResistance. Contrarily, in the same 10 times repeated MIC tests, the second group of $A$. baumannii strains showed unstable COL MICs, as follows: COL MIC values ranging from 1 to $64 \mathrm{mg} / \mathrm{L}$, with the most frequent value being $8 \mathrm{mg} / \mathrm{L}$ in $4 \mathrm{R}$; from 2 to $16 \mathrm{mg} / \mathrm{L}$, with the most frequent value being $16 \mathrm{mg} / \mathrm{L}$ in $5 \mathrm{R}$; from 2 to $128 \mathrm{mg} / \mathrm{L}$, with most frequent values being 64 and $2 \mathrm{mg} / \mathrm{L}$ in $6 \mathrm{R}$ and 7R, respectively; from 2 to $32 \mathrm{mg} / \mathrm{L}$, with the most frequent value being $32 \mathrm{mg} / \mathrm{L}$ in $8 \mathrm{R}$; and from 1 to $128 \mathrm{mg} / \mathrm{L}$ with $4 \mathrm{mg} / \mathrm{L}$ as the most frequent value in $9 \mathrm{R}$ (Table 1$)$. 
Table 1. MICs, e-tests, COL- Population Analysis Profiles (PAP) MICs, LPS, Cell Envelope Charge, and COL-R acquisition phenotype in the COL-R A. baumannii strains.

\begin{tabular}{|c|c|c|c|c|c|c|c|c|c|c|c|c|}
\hline \multirow[b]{2}{*}{ Strain } & \multirow{2}{*}{$\begin{array}{l}\text { COL } \\
\text { MIC } \\
(\mathrm{mg} / \mathrm{L})\end{array}$} & \multirow{2}{*}{$\begin{array}{c}\text { Most } \\
\text { Frequent } \\
\text { COL MIC } \\
(\mathrm{mg} / \mathrm{L})\end{array}$} & \multicolumn{2}{|c|}{$\begin{array}{l}\text { COL-R } \\
\text { Induction }\end{array}$} & \multicolumn{2}{|c|}{$\begin{array}{c}\text { COL PAP } \\
\text { VARIANT MICs }\end{array}$} & \multirow{2}{*}{$\begin{array}{c}\text { LPS } \\
\begin{array}{c}\text { Quantifica- } \\
\text { tion }\end{array} \\
(\mu \mathrm{g} / \mathrm{mL})\end{array}$} & \multirow{2}{*}{$\begin{array}{c}\text { Cell } \\
\text { Envelop } \\
\text { Positive } \\
\text { Charge }\end{array}$} & \multicolumn{4}{|c|}{$\begin{array}{l}\text { AA Substitution in Proteins already Associated to } \\
\text { COL-R }\end{array}$} \\
\hline & & & $\begin{array}{c}\mathrm{COL} \\
\text { Induction }\end{array}$ & $\begin{array}{c}\text { Post } \\
\text { Induction } \\
\text { COL MIC }\end{array}$ & Variant-1 & Variant-2 & & & PmrB & LpxA & GalU & $\begin{array}{c}\text { COL-R } \\
\text { Phenotype }\end{array}$ \\
\hline $1 \mathrm{R}$ & 128 & - & - & - & - & - & 1334.38 & 3.7 & L208F & - & $\begin{array}{l}\text { Q140L } \\
\text { I273V }\end{array}$ & $\begin{array}{c}\text { Full } \\
\text { Resistance }\end{array}$ \\
\hline $2 \mathrm{R}$ & 128 & - & - & - & - & - & 1698.02 & 8.87 & $\mathrm{R} 263 \mathrm{H}$ & - & $\begin{array}{l}\text { Q140L } \\
\text { I273V }\end{array}$ & $\begin{array}{c}\text { Full } \\
\text { Resistance }\end{array}$ \\
\hline $3 R$ & 128 & - & - & - & - & - & 2538.93 & 27.57 & $\begin{array}{l}\text { P170L } \\
\text { A138T }\end{array}$ & N5V & $\mathrm{I} 273 \mathrm{~V}$ & $\begin{array}{c}\text { Full } \\
\text { Resistance }\end{array}$ \\
\hline $4 \mathrm{R}$ & $1-64$ & 8 & NEG & - & 8 & 64 & 257.11 & 49.5 & - & - & $\mathrm{I} 245 \mathrm{~T}$ & $\begin{array}{l}\text { Hetero } \\
\text { Resistance }\end{array}$ \\
\hline $5 R$ & $2-16$ & 16 & NEG & - & 2 & 128 & 1561.65 & 9.8 & - & - & $\begin{array}{l}\text { I245T } \\
\text { S199A }\end{array}$ & $\begin{array}{l}\text { Hetero } \\
\text { Resistance }\end{array}$ \\
\hline $7 \mathrm{R}$ & $2-128$ & 2 & NEG & - & 8 & 64 & 3288.93 & 34.11 & - & - & $\begin{array}{l}\text { I245T } \\
\text { S199A }\end{array}$ & $\begin{array}{l}\text { Hetero } \\
\text { Resistance }\end{array}$ \\
\hline $8 \mathrm{R}$ & $2-32$ & 32 & POS & $>256$ & - & - & 811.66 & 31.7 & $\mathrm{~S} 14 \mathrm{P}$ & - & $\begin{array}{l}\text { I245T } \\
\text { S199A }\end{array}$ & $\begin{array}{l}\text { Adaptive } \\
\text { Resistance }\end{array}$ \\
\hline $9 \mathrm{R}$ & $1-128$ & 4 & NEG & - & 64 & 128 & 2266.20 & 21.02 & S14P & - & $\begin{array}{r}\text { I245T } \\
\text { S199A }\end{array}$ & $\begin{array}{c}\text { Hetero } \\
\text { Resistance }\end{array}$ \\
\hline
\end{tabular}




\subsection{COL Resistance Induction}

Colistin resistance induction assays showed a drug-inducible COL-R phenotype reported as "COL-inducible" onset phenotype in $6 R$ and $8 R$. The induced $6 R$ and $8 R$ variants, having a stable COL MIC $>256 \mathrm{mg} / \mathrm{L}$, were considered as having Adaptive-Resistance. Strains $4 R, 5 R, 7 R$, and 9R showed no growth at colistin concentrations $\geq 2 \mathrm{mg} / \mathrm{L}$ (Table 1).

\subsection{Hetero-Resistance}

COL Population Analysis Profiles (PAPs) revealed the presence of subpopulations able to grow up to COL $64 \mathrm{mg} / \mathrm{L}$ in $4 \mathrm{R}, 5 \mathrm{R}$, and $7 \mathrm{R}$, and up to $128 \mathrm{mg} / \mathrm{L}$ in $9 \mathrm{R}$ A. baumannii, as shown in Figure 1. Furthermore, the presence of two morphologically different subpopulations, named $\mathrm{COL}^{\mathrm{R}}$ variant- 1 and $\mathrm{COL}^{\mathrm{R}}$ variant-2, in $\mathrm{COL} 32 \mathrm{mg} / \mathrm{L}$ agar plates in $4 \mathrm{R}, 5 \mathrm{R}$, and 7R as well as in COL $128 \mathrm{mg} / \mathrm{L}$ agar plates in 9R was also detected (Table 1), (Figure 2). This phenomenon was referred to as "heteroresistance" and identified the "subpopulation" onset phenotype. The $\mathrm{COL}^{\mathrm{R}}$ variant- 1 and $\mathrm{COL}^{\mathrm{R}}$ variant-2 showed a 2 to 6 -fold increase in COL MIC in 4R, 5R, 7R, and a 1- fold COL MIC increase in 9R (Table 1).

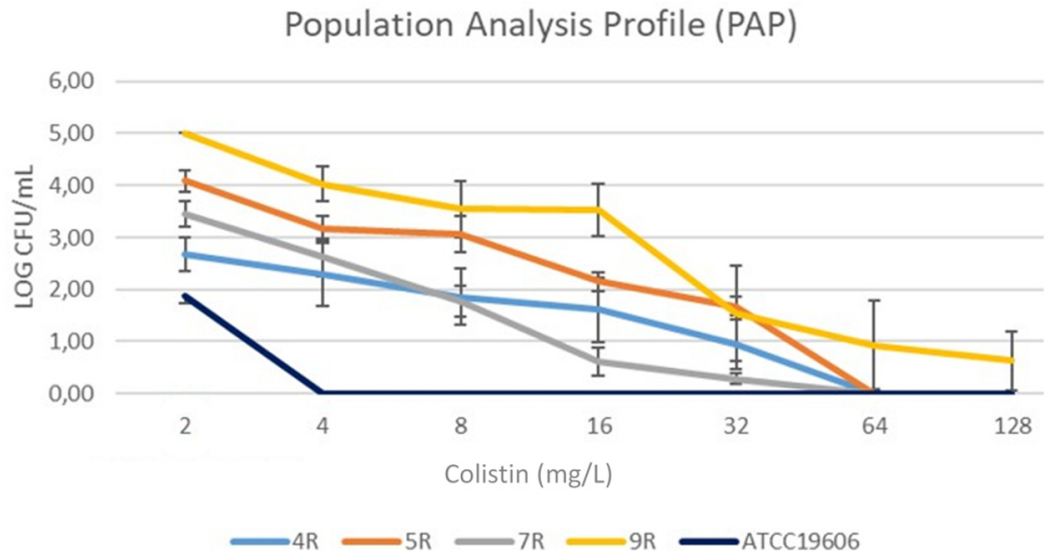

Figure 1. PAPs for the $4 \mathrm{R}, 5 \mathrm{R}, 7 \mathrm{R}$, and $9 \mathrm{R}$ A. baumannii strains.

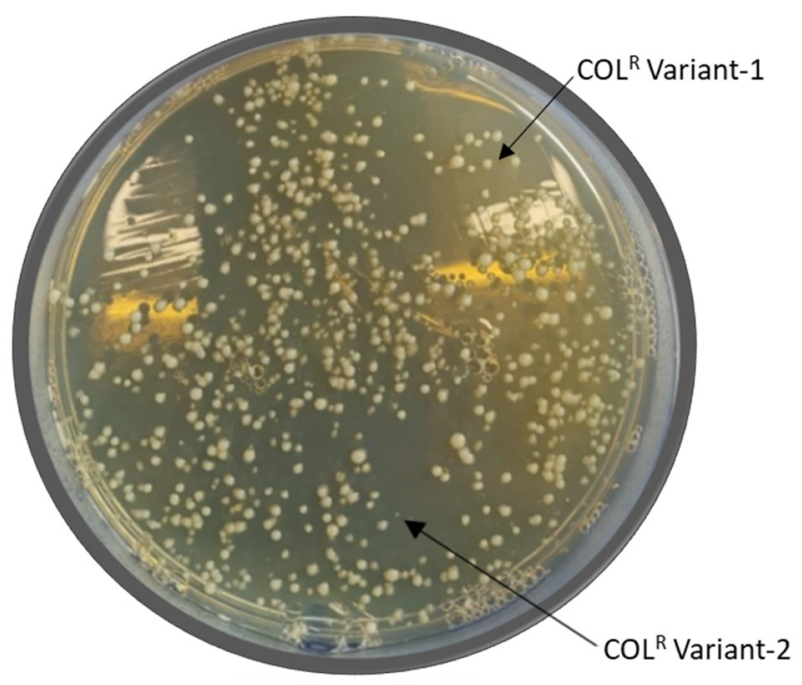

Figure 2. Representative Morphologies of the $\mathrm{COL}^{\mathrm{R}}$ A. baumannii variants detected in $4 \mathrm{R}, 5 \mathrm{R}$, and $7 \mathrm{R}$ detected on $32 \mathrm{mg} / \mathrm{L}$ COL-agar plates and $128 \mathrm{mg} / \mathrm{L}$ COL-agar plates in 9R strains.

\subsection{LPS Quantification and Cell-Envelope Charge}

Lipopolysaccharide (LPS) and cell envelope net positive charge quantification tested in all strains on a normalized total number of bacterial cells are shown in Table 1. 


\subsection{Phylogenetic Tree and Genomic Typing}

Genomic Phylogeny (gPhyl) recognized three different lineages, as shown by the Whole Genome SNP-based phylogenetic tree (Figure 2). 5R, 6R, 7R, 8R, and 9R A. baumannii were grouped in gPhyl lineage-I, 3R, and $4 \mathrm{R}$ in gPhyl lineage-II and $1 \mathrm{R}$ and $2 \mathrm{R}$ in gPhyl lineage-III (Figure 3). gPhyl lineage-I only showed unstable $\mathrm{COL}^{\mathrm{R}}$ A. baumannii, gPhyl lineage-II had one stable and one unstable $\mathrm{COL}^{\mathrm{R}}$ A. baumannii, whereas gPhyl lineage-III only included stable $\mathrm{COL}^{\mathrm{R}}$ A. baumannii.

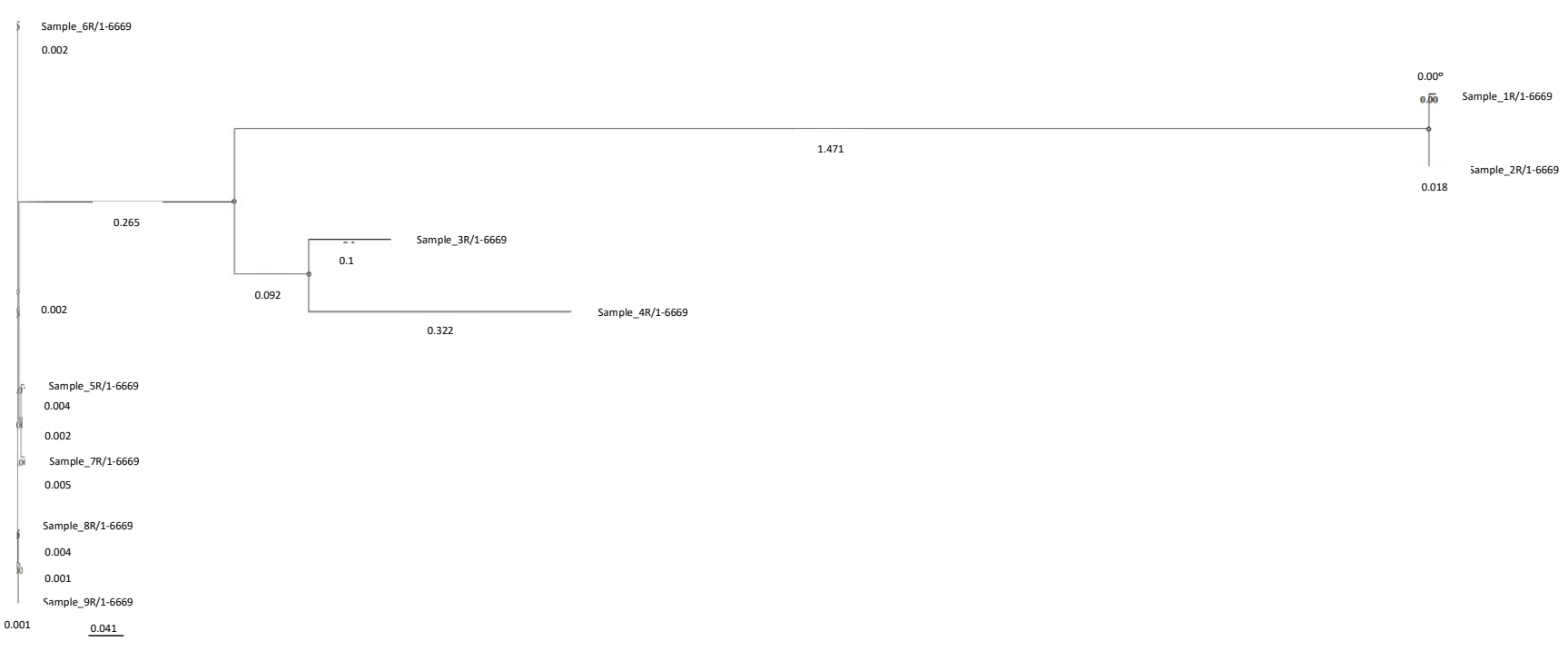

Figure 3. Phylogenetic tree of A. baumannii strains referred to RefGen A. baumanni ACICU, realized with the CSI Phylogeny tool.

According to the Oxford University database, the gPhyl lineage-I A. baumannii strains belonged to the ST-1808 and ST-348, KL-9, and OCL-1 types; the gPhyl lineage-II $A$. baumannii strains belonged to diverse MLSTs (ST-1816 and ST-195 for 3R and ST-218 for 4R) and OCL-1 type, and different KL-3 e and KL-28, respectively; the gPhyl lineage-III A. baumannii belonged to ST-1839 and ST-218 for $1 \mathrm{R}$, having two gdhB alleles with $100 \%$ identity and coverage, along with ST-1839 for 2R, K-22, and OCL-3 types. According to the Pasteur Institute database, all A. baumannii strains were assigned to ST-2, except for $1 \mathrm{R}$, belonging to ST-187, a ST-2 Single Locus Variant (SLV) (Table 2). 
Table 2. Genomic epidemiology and characterization of COL-R A. baumannii.

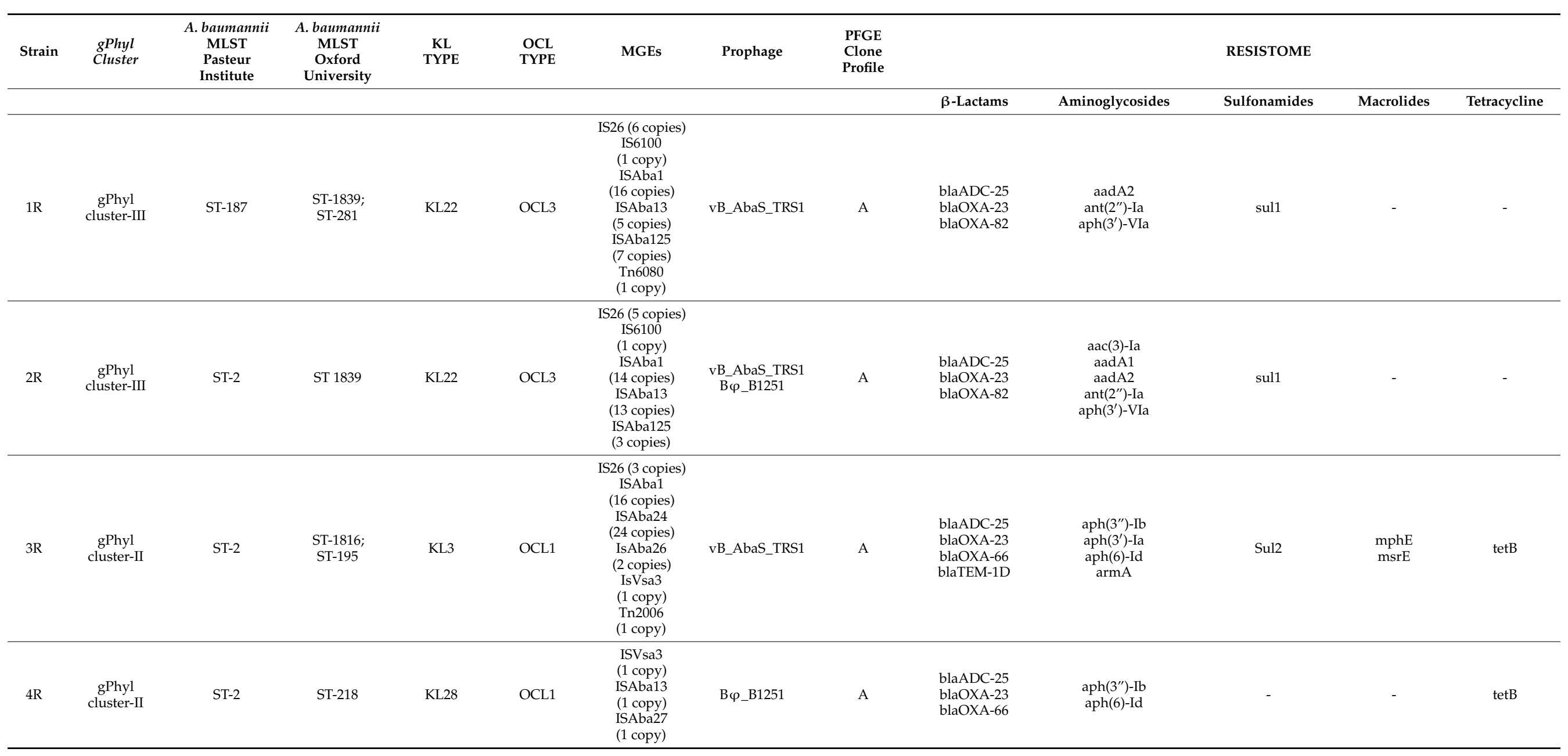


Table 2. Cont.

\begin{tabular}{|c|c|c|c|c|c|c|c|c|c|c|c|c|c|}
\hline Strain & $\begin{array}{l}\text { gPhyl } \\
\text { Cluster }\end{array}$ & $\begin{array}{c}\text { A. baumannii } \\
\text { MLST } \\
\text { Pasteur } \\
\text { Institute }\end{array}$ & $\begin{array}{l}\text { A. baumannii } \\
\text { MLST } \\
\text { Oxford } \\
\text { University }\end{array}$ & $\begin{array}{c}\text { KL } \\
\text { TYPE }\end{array}$ & $\begin{array}{l}\text { OCL } \\
\text { TYPE }\end{array}$ & MGEs & Prophage & $\begin{array}{l}\text { PFGE } \\
\text { Clone } \\
\text { Profile }\end{array}$ & & & RESISTOME & & \\
\hline & & & & & & & & & $\beta$-Lactams & Aminoglycosides & Sulfonamides & Macrolides & Tetracycline \\
\hline $6 \mathrm{R}$ & $\begin{array}{l}\text { gPhyl } \\
\text { cluster-I }\end{array}$ & ST-2 & $\begin{array}{l}\text { ST-1808; } \\
\text { ST-348 }\end{array}$ & KL9 & OCL1 & $\begin{array}{l}\text { IS17 ( } 1 \text { copy) } \\
\text { IS26 } 1 \text { copy) } \\
\text { ISAba1 } \\
\text { ( } 1 \text { copy) } \\
\text { ISAba13 } \\
\text { ( } 1 \text { copy) } \\
\text { ISAba26 } \\
\text { (1 copy) } \\
\text { ISAba36 } \\
\text { ( } 1 \text { copy) } \\
\text { ISVsa3 } \\
\text { ( } 1 \text { copy) } \\
\text { ISEc29(1 copy) }\end{array}$ & & A & $\begin{array}{l}\text { blaADC-25 } \\
\text { blaOXA-66 } \\
\text { blaOXA-72 }\end{array}$ & $\begin{array}{c}\text { aac( }\left(6^{\prime}\right)-\mathrm{Ip} \\
\text { aph(3")-Ib } \\
\text { aph(6)-Id } \\
\operatorname{armA}\end{array}$ & $\begin{array}{l}\text { sul1 } \\
\text { sul2 }\end{array}$ & $\begin{array}{c}\mathrm{mphE} \\
\mathrm{msrE}\end{array}$ & tetB \\
\hline $7 \mathrm{R}$ & $\begin{array}{l}\text { gPhyl } \\
\text { cluster-I }\end{array}$ & ST-2 & $\begin{array}{l}\text { ST-1808; } \\
\text { ST-348 }\end{array}$ & KL9 & OCL1 & $\begin{array}{c}\text { IS17 ( } 1 \text { copy) } \\
\text { IS26 ( } 1 \text { copy) } \\
\text { ISAba1 } \\
\text { (1 copy) } \\
\text { ISAba13 } \\
\text { ( } 1 \text { copy) } \\
\text { ISAba26 } \\
\text { (1 copy) } \\
\text { ISAba36 } \\
\text { ( } 1 \text { copy) } \\
\text { ISVsa3 } \\
\text { (1 copy) } \\
\text { ISEc29( } 1 \text { copy) }\end{array}$ & & A & $\begin{array}{l}\text { blaADC-25 } \\
\text { blaOXA-66 } \\
\text { blaOXA-72 }\end{array}$ & $\begin{array}{l}\text { aph(3")-Ib } \\
\text { aph(6)-Id } \\
\text { armA }\end{array}$ & $\begin{array}{l}\text { sul1 } \\
\text { sul2 }\end{array}$ & $\begin{array}{c}\text { mphE } \\
\text { msrE }\end{array}$ & tetB \\
\hline
\end{tabular}


Table 2. Cont.

\begin{tabular}{|c|c|c|c|c|c|c|c|c|c|c|c|c|c|}
\hline Strain & $\begin{array}{l}\text { gPhyl } \\
\text { Cluster }\end{array}$ & $\begin{array}{l}\text { A. baumannii } \\
\text { MLST } \\
\text { Pasteur } \\
\text { Institute }\end{array}$ & $\begin{array}{l}\text { A. baumannii } \\
\text { MLST } \\
\text { Oxford } \\
\text { University }\end{array}$ & $\begin{array}{c}\text { KL } \\
\text { TYPE }\end{array}$ & $\begin{array}{l}\text { OCL } \\
\text { TYPE }\end{array}$ & MGEs & Prophage & $\begin{array}{l}\text { PFGE } \\
\text { Clone } \\
\text { Profile }\end{array}$ & & & RESISTOME & & \\
\hline & & & & & & & & & $\beta$-Lactams & Aminoglycosides & Sulfonamides & Macrolides & Tetracycline \\
\hline $9 \mathrm{R}$ & $\begin{array}{l}\text { gPhyl } \\
\text { cluster-I }\end{array}$ & ST-2 & $\begin{array}{l}\text { ST-1808; } \\
\text { ST-348 }\end{array}$ & KL9 & OCL1 & $\begin{array}{c}\text { IS17 ( } 1 \text { copy) } \\
\text { IS26 ( } 1 \text { copy) } \\
\text { ISAba1 } \\
\text { ( } 1 \text { copy) } \\
\text { ISAba13 } \\
\text { ( } 1 \text { copy) } \\
\text { ISAba26 } \\
\text { ( } 1 \text { copy) } \\
\text { ISEc29 } \\
\text { ( } 1 \text { copy) } \\
\text { Tn6207 } \\
\text { ( } 1 \text { copy) }\end{array}$ & & A & $\begin{array}{l}\text { blaADC-25 } \\
\text { blaOXA-66 } \\
\text { blaOXA-72 }\end{array}$ & $\begin{array}{l}\operatorname{aph}\left(3^{\prime \prime}\right)-\mathrm{Ib} \\
\text { aph(6)-Id } \\
\operatorname{armA}\end{array}$ & sul1 & $\begin{array}{c}\text { mphE } \\
\text { msrE }\end{array}$ & tetB \\
\hline
\end{tabular}


All A. baumannii lacked the CRISPR/Cas systems, with the exception of 3R carrying 3 questionable (not confirmed) CRISPR regions with 1 spacer, and $6 \mathrm{R}$ having 2 questionable (not confirmed) CRISPR regions with 1 spacer, with both strains lacking Cas genes. Abundant mobile genetic elements including Insertion Sequences and Transposons were found in all A. baumannii, whereas the vB_AbaS_TRS1 and the $\mathrm{B} \varphi \_$B1251 prophages were only found in $1 R, 2 R, 3 R$, and $4 R$. All strains were assigned to the genomic macrorestriction profile " $\mathrm{A}$ ", being indistinguishable by PFGE (Table 2).

\subsection{Resistomes and nsSNPs in Genes Previously Associated to COL-R Mechanisms}

Resistomics showed the acquisition or loss of genes responsible for antimicrobial resistance as reported in Table 2. Based on these data, 4 resistome-types were identified: resistome-type I, characterized by blaADC-25, blaOXA-23, blaOXA-82, aadA2 ant(2")-Ia; aph( $\left.3^{\prime}\right)$-Via, sul1, detected in $1 \mathrm{R}$ and $2 \mathrm{R}$ (gPhyl lineage-III); resistome type-II -blaADC-25; blaOXA-23; blaOXA-66; blaTEM-1D, aph(3")-Ib, aph(3')-Ia, aph(6)-Id; armA, sul2, mphE, $\mathrm{msrE}$, tetB-in 3R (gPhyl lineage-II); resistome type-III-blaADC-25; blaOXA-23, blaOXA66, aph(3")-Ib, aph(6)-Id, tetB-in 4R (gPhyl lineage-II); resistome-type IV-blaADC-25, blaOXA-66, blaOXA-72, aac(6')-Ip, aph(3")-Ib, aph(6)-Id, armA, sul1, sul2 (not always present), mphE, msrE, tetB-in 5R, 6R, 7R, 8R, and 9R (gPhyl lineage-I). No mcr-genes were detected in the unstable and stable $\mathrm{COL}^{\mathrm{R}}$ A. baumannii.

Genomic Single Nucleotide Polymorphisms (SNPs) mapping on A. baumannii ACICU RefGen returned different nsSNPs in genes previously associated with COL-R mechanisms in A. baumannii and other Gram-negative species.

In detail, all unstable members had a characterizing moderate impact effect (MI) galU nsSNP determining the I245T AminoAcid (AA) change, whilst only 3 out of 6 showed pmrB nsSNPs. All stable COL full resistant members had diverse MI nsSNPs in both galU and $p m r$ B. Furthermore, all the stable COL full resistant members had the galU nsSNP determining the I273V associated, in two strains, to the Q140L, along with two AA changes in PmrB (P170L and A138T) and one in LpxA (N5V) (Table 1).

No nsSNPs were detected in $p m r \mathrm{AC}, \operatorname{lp} x \mathrm{DCB}$, and proB in all A. baumannii on $A$. baumannnii ACICU RefGen mapping.

\section{Discussion}

The outbreak of antibiotic resistance and the emergence of MDR A. baumannii highlight the need to understand how resistant strains emerge and spread. The overuse and inappropriate consumption of colistin strongly correlate with the emergence of $\mathrm{COL}^{\mathrm{R}} A$. baumannii [18].

Colistin resistance in A. baumannii has been reported worldwide, with the highest resistance rates in Asia and then in Europe [19]; however, the rate of colistin heteroresistance in A. baumannii turned out to be higher than that of resistance $[9,20-23]$.

In this context, we investigated the stability of COL-R phenotypes in A. baumannii phenotypically outlining the different onset strategies and genomically characterizing the phylogenetic lineages having different "stability and onset phenotypes".

Our data, for the first time, described the phenomenon of the variable behavior of the COL-R phenotype in a group of clinical A. baumannii. Our observations of the MIC values, repeated several times, lead us to conclude that a stable COL-R phenotype was exhibited only in 3 out of 9 A. baumannii. In A. baumannii, high levels of COL-R (MIC $128 \mathrm{mg} / \mathrm{L}$ ) were detected within the entire bacterial population emerging, thus, with a "homogeneousresistant" onset phenotype, and hence considered as "Full-Resistance". The Full-Resistant $A$. baumannii were already described and our data was in agreement with previously published data and well-characterized strains $[2,24]$. Contrarily, the COL-R phenotype instability was described by our group, for the first time, in 6 A. baumannii showing mainly variable and lower COL MICs ranging from 1 to $128 \mathrm{mg} / \mathrm{L}$. This original observation opens a new perspective in the understanding of the COL-R emergence strategies under colistin 
pressure and could be crucial for the clinical implication in the treatment of severe MDR Gram-negative infections.

The unstable COL-R phenotype was related by our group to two different onset strategies, i.e., a "COL-inducible" onset phenotype, considered as an "Adaptive Resistance" -in agreement to prior observations [25,26] - and a "Subpopulation" onset phenotype considered as "Heteroresistance" previously described by another group [27]. In our A. baumannii, the "COL-inducible" onset-phenotype emerged via an induction mechanism related to a constant long term colistin exposure, whilst the "Subpopulation" onset-phenotype emerged spontaneously in a subset of populations with higher COL-R levels, detectable as morphological variants with different COL MICs, exclusively in the presence of high COL concentrations (i.e., $\geq \mathrm{COL} 32 / 128 \mathrm{mg} / \mathrm{L}$ agar plates).

No correlation was found between the COL-R stability and the different onset strategies with LPS amount and cell-envelope charge. Therefore, we hypothesized that LPS alterations and perturbations in the negative envelope charge can exist as single or coexisting features, although in a strain-dependent manner and independently to the stability of the COL-R phenotype. In our opinion, the co-occurrence of a pool of the two factors might affect the envelope structure and charge both directly and/or indirectly.

Genomic Phylogeny arises firstly new consideration about the dynamics of $\mathrm{COL}^{\mathrm{R}}$ stable phenotype emergence, leading us to evidence that the progression from an unstable and stable phenotype appeared related to specific phylogenetic lineages characterized by high genomic mosaicism due to acquisition or loss of MGEs or Phages. The Genomic Phylogeny clustered our clinical A. baumannii sample in 3 phylogenetic lineages and the phylogram indicated gPhyl lineage-I as the common ancestor of gPhyl lineage-II and gPhyl lineage-III. Interestingly, gPhyl lineage-I only included unstable $\mathrm{COL}^{\mathrm{R}} A$. baumannii with hetero- or adaptive COL-R, gPhyl lineage-II clustered one stable, homogeneous, COL Full-Resistant A. baumannii together with one unstable, heteroresistant $\mathrm{COL}^{\mathrm{R}}$ A. baumannii, whereas gPhyl lineage-III only included stable, homogeneous Full-Resistant $\mathrm{COL}^{\mathrm{R}}$ A. baumannii. Notably, the analysis of the evolutionary relationship of the gPhyl lineages clearly showed that gPhyl lineage-II, including unstable and stable COL-R phenotypes, may be considered as a "hybrid lineage" branching out from gPhyl lineage-I as a midpoint in the evolution of these strains, whereas gPhyl lineage-III, last differentiated, with only stable Full-Resistant $\mathrm{COL}^{\mathrm{R}}$ A. baumannii, may be considered as an endpoint in the $\mathrm{COL}^{\mathrm{R}}$ A. baumannii strain evolution, in agreement with the progression of COL-R stability acquisition.

This described phylogenetic evolution for the first time supports the hypothesis that the acquisition of a stable, homogeneous, full COL-R moves its first steps in the subpopulation or the adaptive onset strategy that progresses until reaching stability and homogeneity.

Furthermore, the gPhyl lineage-I A. baumannii strains belonged to the ST-1808 and ST-348, KL-9, OCL-1, and resistome-IV type; the gPhyl lineage-II A. baumannii strains belonged to diverse MLSTs (ST-1816 and ST-195 for 3R and ST-218 for 4R), KL-3 or KL-28, OCL-1, and resistome-II or III type; the gPhyl lineage-III A. baumannii strains belonged both to the ST-1839, KL-22, OCL-3, and resistome-I type, showing that belonging to a specific gPhyl lineage is related to intrinsic clonality of its members. By contrast, the mobilome and prophage profile showed a mosaic of mobile genetic elements (MGEs) and phages ranging from a higher number of transposable elements, such as 6-8 different insertion sequence elements (ISs) and one transposon (Tn6207) in gPhyl lineage-I unstable COLR A. baumannii, to a lower IS set (3-6) and one transposon (Tn6080 or Tn2006) associated to one and/or two different phages (vB_AbaS_TRS1 and the B $\varphi \_$B1251) as in gPhyl lineage-II and III. The MGE and phage toolbox showed dynamism inside the highly clonal conserved A. baumannii genomes, resulting in increased variability and complexity related to the transition from an unstable to a stable COL-R phenotype, besides being responsible for genome evolution and high antimicrobial adaptation ability. Furthermore, resistomics highlighted that the gPhyl lineage-III — with its stable, homogeneous and full resistancesurprisingly appeared short of acquired resistance determinants, such as the genes involved 
in tetracycline and macrolide resistance, with respect to the other two mainly unstable phylogenomic lineages.

Furthermore, we can speculate that genetic variations in genes already related to polymyxin $\mathrm{B}(\mathrm{PB})$ and COL resistance seem, for the first time, related to the progression towards a stable $\mathrm{COL}^{\mathrm{R}}$ phenotype. New mutations in galU_ encoding an enzyme related to polymyxin B (PB) resistance in Proteus mirabilis [28] - and in pmrB, involved in the COL-R in A. baumannii [4] and Enterobacterales [29], were found out in the sample. New nsSNPs, computationally predicted affecting protein functionality, were mapped in GalU ligand binding site I245T in the unstable $\mathrm{COL}^{\mathrm{R}}$ and I273V in the stable one. GalU-UTPglucose-1-phosphate uridylyltransferase is a key enzyme involved in the pathway of the lipopolysaccharide biosynthesis, which is part of outer membrane biogenesis [30]. P. mirabilis knockout mutants in GalU were found to be extremely sensitive to PB, presumably because of changes in LPS [29]. Likewise, no mcr-mediated resistance mechanisms are implicated in the stability of COL-R phenotypes as mcr-genes were not found [6].

Of note, the genomic snapshot of the three different "COL-R onset phenotypes showed that the progression from COL-R instability to stability seems to be associated with a gradual genome evolution from "low-complexity" to "high-complexity" lineages through a pool of complex rearranged genomes.

In conclusion, our investigation finds out a new correlation between the in vitro COL$\mathrm{R}$ stability and onset strategies as well as the membership to specific phylogenetic lineages evolving through complex genomic rearrangements involving whole-genome SNPomes, MGEs, Resistomes, Phage Profiling.

Our data demonstrated, for the first time, the association between the shift to unstable to stable COL-R phenotypes and increasing genomic mosaicism within the intrinsic high clonality of $\mathrm{COL}^{\mathrm{R}}$ A. baumannii. Likewise, new mutations putatively affecting the stability and functionality of GalU and PmrB can speculatively affect the dynamics of the COL-R stability acquisition.

\section{Materials and Methods}

\subsection{Bacterial Strains}

Nine clinical Extensively Drug-Resistant (XDR) A. baumannii, named 1-9R, were isolated from patients treated with sodium colistithemate for a long time, 7-14 days, at the Catania and Pisa University Hospitals (Table 3)

Table 3. Clinical COL-R A. baumannii.

\begin{tabular}{cll}
\hline Strain & \multicolumn{1}{c}{ Hospital Wards } & \multicolumn{1}{c}{ Source } \\
\hline $1 \mathrm{R}$ & Anesthesia and Intensive care & Bronchial aspirate \\
\hline $2 \mathrm{R}$ & Anesthesia and Intensive care & Bronchial aspirate \\
\hline $3 \mathrm{R}$ & Anesthesia and Intensive care & Bronchial aspirate \\
\hline $4 \mathrm{R}$ & Anesthesia and Intensive care & Bronchial aspirate \\
\hline $5 \mathrm{R}$ & Anesthesia and Intensive care & Bronchial aspirate \\
\hline $6 \mathrm{R}$ & Anesthesia and Intensive care & Bronchial aspirate \\
\hline $7 \mathrm{R}$ & Burns Unit & Blood culture \\
\hline $8 \mathrm{R}$ & Anesthesia and Intensive care & Blood culture \\
\hline $9 \mathrm{R}$ & Orthopedics and Traumatology & Wound swab \\
\hline
\end{tabular}

The strains were grown in McConkey agar plates (Oxoid, UK) at $37^{\circ} \mathrm{C}$ for $18 \mathrm{~h}$ and identified by Matrix-Assisted Laser Desorption Ionization-Time of Flight (MALDITOF) [31] mass spectrometry (Bruker Daltonics, Billerica, MA, USA). Antibiotypes were determined by the Phoenix system (Becton, Dickinson and Company, MD, USA) [32] and 
the results were confirmed by the Sensititre system (Thermo Fisher Scientific, Waltham, MA, USA) [33]. The strains were stored in glycerol at $-80^{\circ} \mathrm{C}$ until further analysis.

\subsection{COL Minimum Inhibitory Concentrations (MICs)}

Colistin MICs were determined by microdilution assay using sulfate colistin $\geq 15,000 \mathrm{U} / \mathrm{mg}$ (Sigma-Aldrich, Castle Hill, New Galles, Australia) in cation-adjusted MullerHinton broth (BBLTM MHBCA II; Becton, Dickinson and Company, MD, USA) as recommended by the Clinical and Laboratory Standards Institute (CLSI) [34] and the EUCAST guidelines. The results were interpreted according to the current colistin breakpoints for A. baumannii reported in EUCAST v9.0 [35] ( $\leq 2 \mathrm{mg} / \mathrm{L}$ for COL-susceptibility (COL-S) and $>2 \mathrm{mg} / \mathrm{L}$ for COL-resistance (COL-R)). Pseudomonas aeruginosa ATCC27853 and Escherichia coli ATCC25922 were used as control strains for these assays. MIC assays were repeated 10 times almost every week for three months.

\subsection{COL Resistance Induction Assay}

COL-R induction assays were performed by growing daily A. baumannii strains at COL concentrations gradually doubled from COL $0.5 \mathrm{mg} / \mathrm{L}$ to COL $32 \mathrm{mg} / \mathrm{L}$ in Brain-Heart Infusion Broth (BHIB-Oxoid, Basingstoke, UK). Then, colistin resistance was re-evaluated by plating cultures in COL $16 \mathrm{mg} / \mathrm{L}$ agar-plates and the COL MICs were re-evaluated as described above. Each COL-R induction assay was performed in three biological replicates.

\subsection{COL Hetero-Resistance Detection}

Population Analysis Profiles (PAPs) were defined to evaluate the presence of $A$. baumannii subpopulations with a diverse rate of COL-R $[9,36]$. PAPs were performed by plating $50 \mu \mathrm{L}$ of a $10^{8} \mathrm{CFU} / \mathrm{mL}$ bacterial suspension in Mueller-Hinton (MH) agar containing serial dilutions $(2-128 \mathrm{mg} / \mathrm{L})$ of sulfate colistin. After $48 \mathrm{~h}$ of incubation at $37^{\circ} \mathrm{C}$, the presence of "differential rate" COL-R subpopulations were evaluated. A. baumannii ATCC19606 was used as the control strain. For each subpopulation, "differential rate" COL-R detection was performed in triplicate.

\subsection{Surface Charge Determination}

The cytochrome $c$ binding assay was performed as a surrogate measure of the relative net positive surface charge of the strain as previously described [37,38]. Briefly, cells were grown overnight in TSB media to an $\mathrm{OD}_{575}=10\left(2 \times 10^{10} \mathrm{CFU} / \mathrm{mL}\right)$, washed with $20 \mathrm{mM}$ MOPS buffer ( $\mathrm{pH}$ 7.0) three times, and re-suspended in the same buffer at $\mathrm{OD}_{575}=10$ $\left(2 \times 10^{10} \mathrm{CFU} / \mathrm{mL}\right)$. Cells were incubated with $0.5 \mathrm{mg} / \mathrm{mL}$ cytochrome $c$ for $10 \mathrm{~min}$ and the amount of cytochrome $c$ remaining in the supernatant was determined spectrophotometrically at $\mathrm{OD}_{530} \mathrm{~nm}$. The greater the amount of unbound cytochrome $c$ detected in the supernatant, the higher the net positive charge of the bacterial surface. Data were converted and expressed as the mean $( \pm \mathrm{SD})$ amount of bound cytochrome $c$. At least three independent runs were performed on separate days.

\subsection{Direct LPS Quantification}

LPS was extracted by the hot phenol-water method as previously described $[39,40]$. Briefly, each A. baumannii culture was grown up to $\mathrm{OD}_{650}=10\left(2 \times 10^{10} \mathrm{CFU} / \mathrm{mL}\right)$ in Cation adjusted Mueller Hinton broth, and cells were harvested by centrifuging the tubes at $10,000 \times g$ for $5 \mathrm{~min}$. The pellets were washed twice in PBS $(\mathrm{pH}=7.2,0.15 \mathrm{M})$ containing $0.15 \mathrm{mM} \mathrm{CaCl}_{2}$ and $0.5 \mathrm{mM} \mathrm{MgCl}_{2}$, then they were resuspended in $10 \mathrm{~mL}$ PBS and sonicated for $10 \mathrm{~min}$ on ice. Treatments with proteinase $\mathrm{K}(100 \mu \mathrm{g} / \mathrm{mL})$ at $65^{\circ} \mathrm{C}$ for $1 \mathrm{~h}$, and with DNase $(20 \mu \mathrm{g} / \mathrm{mL})$ and RNase $(40 \mu \mathrm{g} / \mathrm{mL})$ incubating the pellet at $37^{\circ} \mathrm{C}$ overnight in the presence of $1 \mu \mathrm{L} / \mathrm{mL} 20 \% \mathrm{MgSO}_{4}$ and $4 \mu \mathrm{L} / \mathrm{mL}$ chloroform, were performed prior to extraction step to eliminate contaminating protein and nucleic acids. Subsequently, an equal volume of hot $\left(65-70^{\circ} \mathrm{C}\right) 90 \%$ phenol was added to the mixtures followed by vigorous shaking at $65-70{ }^{\circ} \mathrm{C}$ for $15 \mathrm{~min}$. Suspensions were then cooled on ice, transferred to $1.5 \mathrm{~mL}$ 
polypropylene tubes, and centrifuged at $8500 \times g$ for an additional $15 \mathrm{~min}$. Supernatants were transferred to $15 \mathrm{~mL}$ conical centrifuge tubes and phenol phases were re-extracted using $300 \mu \mathrm{L} \mathrm{dH_{2 }} \mathrm{O}$. Sodium acetate at $0.5 \mathrm{M}$ final concentration and 10 volumes of $95 \%$ ethanol were added to the extracts and samples were stored at $-20^{\circ} \mathrm{C}$ overnight to allow LPS precipitation. On the last day, tubes were centrifuged at $2000 \times g 4^{\circ} \mathrm{C}$ for $10 \mathrm{~min}$ and

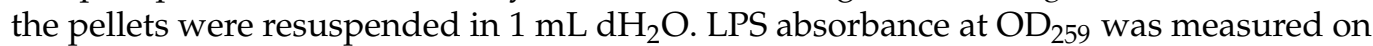
the same day in a spectrophotometer (Thermo Scientific ${ }^{\mathrm{TM}}$ GENESYS 10S UV-Vis, Waltham, MA, USA), and the quantification was obtained by comparison with a standard curve made with scalar dilutions of extra pure E. coli LPS (Sigma, St. Louis, MO, USA).

\subsection{Genotyping}

Chromosomal DNA for Pulsed-Field Gel Electrophoresis (PFGE) was prepared as previously described [41-43]. DNA was digested with ApaI 30 U (New England Biolabs, Beverly, MA, USA) at $25^{\circ} \mathrm{C}$ for $2 \mathrm{~h}$ and analyzed on a Conturn-Clamped Homogenous Electric Field (CHEF DRII) [40] (Bio-Rad Laboratories, Hercules, CA, USA) with the following PFGE parameters: $20 \mathrm{~h}$ at $14{ }^{\circ} \mathrm{C}$ in $0.5 \times$ TBE buffer at $6 \mathrm{~V} / \mathrm{cm}$, with a forward pulse time of $5 \mathrm{~s}$ for $5 \mathrm{~h}, 10 \mathrm{~s}$ for $5 \mathrm{~h}, 22 \mathrm{~s}$ for $5 \mathrm{~h}$, and $35 \mathrm{~s}$ for $5 \mathrm{~h}$. A $\lambda$ ladder PFGE marker was included in each run as the molecular size standard. Genetic relatedness, based on the ApaI PFGE profiles, was calculated by unweighted pair-group method analysis (UPGMA) [41]. A. baumannii strains clusters with $>85 \%$ similarity were considered as belonging to the same PFGE clone [42,43].

\subsection{Whole Genome Sequencing (WGS)}

Genomic DNA was extracted using the PureLink Genomic DNA Mini Kit (Invitrogen, Waltham, MA, USA) following the manufacture's protocol. DNA quality was evaluated using Qubit and its concentration was determined by Picogreen (Life Technologies, Carlsbad, CA, USA). Whole Genome Sequencing (WGS) was performed with the Illumina Mi-seq 300P sequencing system using paired-end (PE) read libraries prepared by Nextera XT DNA Library Preparation Kit (Illumina, San Diego, CA, USA) following the manufacture's proto$\mathrm{col}$, and the quality was evaluated as previously published [2]. The indexed libraries were quantified as previously published [2], pooled at a final concentration of $2 \mathrm{nM}$, and used for Illumina MiSeq sequencing with a PE $300(2 \times 300 \mathrm{bp})$. Raw reads were processed with QUAST (v.4.6.3) for quality evaluation, and the Cutadapter tool (v.1.16) implemented in Phyton (v.3.5.2) was employed to remove residual PCR primers, low-quality (Q_score < 30), and short reads $(<150 \mathrm{bp})$. The filtered trimmed reads were used for downstream analysis. De novo genome assembly was performed with the SPAdes software (v.3.12.0) generating contig files for each sample. Post-assembly metrics were evaluated by QUAST (v.4.6.3).

\subsection{Phylogeny and Genomic Epidemiology}

The CSI Phylogeny tool was used to study the genomic relationship of strains. On the other hand, genomic epidemiology was assessed by the ResFinder (v4.1) and K-mer Resistance (v.2.2) tools to identify acquired antimicrobial resistance (AMR) genes and the known non-synonymous SNPs (nsSNPs) correlated to AMR genes using a threshold of $98 \%$ for nucleotide sequence identity and a minimum coverage of 60\% [44]. Multi Locus Sequence Typing (MLST) was genomically determined using the MLST software (v1.8) [45] according to the Oxford University and Pasteur Institute databases, Mobile genetic elements (MGEs) were searched using Mobile element Finder (v1.0.3) [46] and prophages using the PHAge Search Tool (PHAST) [47] considering only the prophage regions detected with a completeness score $>90$. CRISPRFinder was used to identify the presence of CRISPR/Cas systems and spacers in the genomes studied. CRISPR array type was assessed using CRISPRCasdb, where CRISPR4 represents level 4 CRISPRs (the most reliable ones), while CRISPR levels 1 , 2 , and 3 can be considered as false CRISPRs [48]. Kaptive, a tool based on the variability of outer-core (OC) components of the lipooligosaccharide (LOS) forming a lipopolysaccharide (LPS) and $\mathrm{K}$ locus $(\mathrm{KL})$ involved in the synthesis of the capsular polysaccharide (CPS, $\mathrm{K}$, 
or capsule), was used to investigate the bacterial surface polysaccharide locus typing and variant evaluation $[49,50]$.

\subsection{Single Nucleotide Polymorphisms (SNPs)}

Single Nucleotide Polymorphism (SNP) calls were carried out from the PE library raw reads as already published [2]. A. baumannii ACICU (CP000863.1) genome was used as the reference genome sequence for SNP mapping.

\subsection{Genomic Single-Nucleotide Polymorphism Effect Prediction}

The prediction of the whole-genome SNPs (SNPome) effects was performed by SnpEff (v.4.3T), a genomic variant annotation and functional effect prediction toolbox as previously published [51,52].

Author Contributions: V.C. and S.S. (Stefania Stefani) conceived and designed the study. V.C., S.S. (Stefano Stracquadanio), F.L.V., V.D. and A.Z. performed the phenotype experiments and bioinformatics. E.G. and S.B. provided the Pisa sample. G.P. contributed to the bioinformatic analysis. All authors have read and agreed to the published version of the manuscript.

Funding: This study was supported by a research grant, PRIN2017SFBFER, from MIUR, Italy. "Starting Grant" of the "Piano di incentivi per la ricerca di Ateneo" Prot. n. 253556 del 16 marzo 2021University of Catania.

Institutional Review Board Statement: Not applicable.

Informed Consent Statement: Not applicable.

Data Availability Statement: The genomic reads were deposited in the National Center for Biotechnology Information (NCBI) Genome database in the Sequence Read Archive (SRA), namely 1R and 2R under study accession no. SRP133297 (BioProject: PRJNA435581) and 3-9R under study accession no. SRP166981 (BioProject: PRJNA717714).

Acknowledgments: We wish to thank PharmaTranslated for language support.

Conflicts of Interest: The authors declare no conflict of interest.

\section{References}

1. Sievert, D.M.; Ricks, P.; Edwards, J.R.; Schneider, A.; Patel, J.; Srinivasan, A.; Kallen, A.; Limbago, B.; Fridkin, S.; National Healthcare Safety Network (NHSN) Team and Participating NHSN Facilities. Antimicrobial-resistant pathogens associated with healthcare-associated infections: Summary of data reported to the National Healthcare Safety Network at the Centers for Disease Control and Prevention, 2009-2010. Infect. Control Hosp. Epidemiol. 2013, 34, 1-14. [CrossRef]

2. Cafiso, V.; Stracquadanio, S.; Lo Verde, F.; Gabriele, G.; Mezzatesta, M.L.; Caio, C.; Pigola, G.; Ferro, A.; Stefani, S. Colistin Resistant A. baumannii: Genomic and Transcriptomic Traits Acquired under Colistin Therapy. Front. Microbiol. $2019,9,3195$. [CrossRef] [PubMed]

3. Ilsan, N.A.; Lee, Y.-J.; Kuo, S.-C.; Lee, I.-H.; Huang, T.-W. Antimicrobial Resistance Mechanisms and Virulence of Colistinand Carbapenem-Resistant Acinetobacter baumannii Isolated from a Teaching Hospital in Taiwan. Microorganisms 2021, 9, 1295. [CrossRef]

4. Wand, M.E.; Bock, L.J.; Bonney, L.C.; Sutton, J.M. Retention of virulence following adaptation to colistin in Acinetobacter baumannii reflects the mechanism of resistance. J. Antimicrob. Chemother. 2015, 70, 2209-2216. [CrossRef]

5. Geisinger, E.; Isberg, R.R. Antibiotic modulation of capsular exopolysaccharide and virulence in Acinetobacter baumannii. PLoS Pathog. 2015, 11, e1004691. [CrossRef]

6. Martins-Sorenson, N.; Snesrud, E.; Xavier, D.E.; Cacci, L.C.; Iavarone, A.T.; McGann, P.; Riley, L.W.; Moreira, B.M. A novel plasmid-encoded mcr-4.3 gene in a colistin-resistant Acinetobacter baumannii clinical strain. J. Antimicrob. Chemother. 2020, 75, 60-64. [CrossRef]

7. Sacco, F.; Visca, P.; Runci, F.; Antonelli, G.; Raponi, G. Susceptibility Testing of Colistin for Acinetobacter baumannii: How Far Are We from the Truth? Antibiotics 2021, 10, 48. [CrossRef] [PubMed]

8. Karakonstantis, S.; Saridakis, I. Colistin heteroresistance in Acinetobacter spp.: Systematic review and meta-analysis of the prevalence and discussion of the mechanisms and potential therapeutic implications. Int. J. Antimicrob. Agents 2020, $56,106065$. [CrossRef]

9. Li, J.; Rayner, C.R.; Nation, R.L.; Owen, R.J.; Spelman, D.; Tan, K.E.; Liolios, L. Heteroresistance to colistin in multidrug-resistant Acinetobacter baumannii. Antimicrob. Agents Chemother. 2006, 50, 2946-2950. [CrossRef] 
10. Rasidin, R.S.M.; Suhaili, Z.; Mohamed, A.F.S.; Hod, R.; Neela, V.; Amin-Nordin, S. Time-kill and post-antibiotic effect of colistin at different static concentrations in in vitro Acinetobacter baumannii. Trop. Biomed. 2020, 37, 471-481. [PubMed]

11. Andersson, D.I.; Nicoloff, H.; Hjort, K. Mechanisms and clinical relevance of bacterial heteroresistance. Nat. Rev. Microbiol. 2019, 17, 479-496. [CrossRef] [PubMed]

12. Çağlan, E.; Nigiz, Ş.; Sancak, B.; Gür, D. Resistance and heteroresistance to colistin among clinical isolates of Acinetobacter baumannii. Acta Microbiol. Immunol. Hung. 2020, 67, 107-111. [CrossRef] [PubMed]

13. Ezadi, F.; Jamali, A.; Heidari, A.; Javid, N.; Ardebili, A. Heteroresistance to colistin in oxacillinase-producing carbapenem-resistant Acinetobacter baumannii clinical isolates from Gorgan, Northern Iran. J. Glob. Antimicrob. Resist. 2020, 21, 380-385. [CrossRef] [PubMed]

14. Thet, K.T.; Lunha, K.; Srisrattakarn, A.; Lulitanond, A.; Tavichakorntrakool, R.; Kuwatjanakul, W.; Charoensri, N.; Chanawong, A. Colistin heteroresistance in carbapenem-resistant Acinetobacter baumannii clinical isolates from a Thai university hospital. World J. Microbiol. Biotechnol. 2020, 36, 102. [CrossRef]

15. Chen, L.; Lin, J.; Lu, H.; Zhang, X.; Wang, C.; Liu, H.; Zhang, X.; Li, J.; Cao, J.; Zhou, T. Deciphering colistin heteroresistance in Acinetobacter baumannii clinical isolates from Wenzhou, China. J. Antibiot. 2020, 73, 463-470. [CrossRef]

16. Charretier, Y.; Diene, S.M.; Baud, D.; Chatellier, S.; Santiago-Allexant, E.; van Belkum, A.; Guigon, G.; Schrenzel, J. Colistin Heteroresistance and Involvement of the PmrAB Regulatory System in Acinetobacter baumannii. Antimicrob Agents Chemother. 2018, 62, e00788-18. [CrossRef]

17. Machado, D.; Antunes, J.; Simões, A.; Perdigão, J.; Couto, I.; McCusker, M.; Martins, M.; Portugal, I.; Pacheco, T.; Batista, J.; et al. Contribution of efflux to colistin heteroresistance in a multidrug resistant Acinetobacter baumannii clinical isolate. J. Med. Microbiol. 2018, 67, 740-749. [CrossRef]

18. El-Sayed Ahmed, M.A.E.; Zhong, L.L.; Shen, C.; Yang, Y.; Doi, Y.; Tian, G.B. Colistin and its role in the Era of antibiotic resistance: An extended review (2000-2019). Emerg. Microbes. Infect. 2020, 9, 868-885. [CrossRef] [PubMed]

19. Cai, Y.; Chai, D.; Wang, R.; Liang, B.; Bai, N. Colistin resistance of Acinetobacter baumannii: Clinical reports, mechanisms and antimicrobial strategies. J. Antimicrob. Chemother. 2012, 67, 1607-1615. [CrossRef] [PubMed]

20. Herrera, M.E.; Mobilia, L.N.; Posse, G.R. Comparative evaluation of the sensitivity of Acinetobacter to colistin, using the prediffusion and minimum inhibitory concentration methods: Detection of heteroresistant isolates. Rev. Argent. Microbiol. 2011, 43, 115-119. [CrossRef] [PubMed]

21. Rodriguez, C.H.; De Ambrosio, A.; Bajuk, M.; Spinozzi, M.; Nastro, M.; Bombicino, K.; Radice, M.; Gutkind, G.; Vay, C.; Famiglietti, A. In vitro antimicrobials activity against endemic Acinetobacter baumannii multiresistant clones. J. Infect. Dev. Ctries. 2010, 4, 164-167. [CrossRef]

22. Rodriguez, C.H.; Bombicino, K.; Granados, G.; Nastro, M.; Vay, C.; Famiglietti, A. Selection of colistin-resistant Acinetobacter baumannii isolates in postneurosurgical meningitis in an intensive care unit with high presence of heteroresistance to colistin. Diagn. Microbiol. Infect. Dis. 2009, 65, 188-191. [CrossRef]

23. Yau, W.; Owen, R.J.; Poudyal, A.; Bell, J.M.; Turnidge, J.D.; Yu, H.H.; Nation, R.L.; Li, J. Colistin hetero-resistance in multidrugresistant Acinetobacter baumannii clinical isolates from the Western Pacific region in the SENTRY antimicrobial surveillance programme. J. Infect. 2009, 58, 138-144. [CrossRef]

24. Barin, J.; Martins, A.F.; Heineck, B.L.; Barth, A.L.; Zavascki, A.P. Hetero- and adaptive resistance to polymyxin B in OXA-23producing carbapenem-resistant Acinetobacter baumannii isolates. Ann. Clin. Microbiol. Antimicrob. 2013, 12, 15. [CrossRef] [PubMed]

25. Cafiso, V.; Stracquadanio, S.; Lo Verde, F.; Dovere, V.; Zega, A.; Pigola, G.; Aranda, J.; Stefani, S. COLR Acinetobacter baumannii sRNA Signatures: Computational Comparative Identification and Biological Targets. Front. Microbiol. 2020, 10, 3075. [CrossRef] [PubMed]

26. Motta, S.S.; Cluzel, P.; Aldana, M. Adaptive resistance in bacteria requires epigenetic inheritance, genetic noise, and cost of efflux pumps. PLoS ONE 2015, 10, e0118464. [CrossRef]

27. Falagas, M.E.; Makris, G.C.; Dimopoulos, G.; Matthaiou, D.K. Heteroresistance: A concern of increasing clinical significance? Clin. Microbiol. Infect. 2008, 14, 101-104. [CrossRef] [PubMed]

28. Jiang, S.S.; Lin, T.Y.; Wang, W.B.; Liu, M.C.; Hsueh, P.R.; Liaw, S.J. Characterization of UDP-glucose dehydrogenase and UDPglucose pyrophosphorylase mutants of Proteus mirabilis: Defectiveness in polymyxin B resistance, swarming, and virulence. Antimicrob. Agents Chemother. 2010, 54, 2000-2009. [CrossRef] [PubMed]

29. Olaitan, A.O.; Morand, S.; Rolain, J.M. Mechanisms of polymyxin resistance: Acquired and intrinsic resistance in bacteria. Front. Microbiol. 2014, 5, 643. [CrossRef] [PubMed]

30. French, S.; Farha, M.; Ellis, M.J.; Sameer, Z.; Côté, J.P.; Cotroneo, N.; Lister, T.; Rubio, A.; Brown, E.D. Potentiation of Antibiotics against Gram-Negative Bacteria by Polymyxin B Analogue SPR741 from Unique Perturbation of the Outer Membrane. ACS Infect. Dis. 2020, 6, 1405-1412. [CrossRef] [PubMed]

31. Overview Microflex Series—Highest Performance Bench-Top MALDI-TOF, MS Bruker.com. Available online: https://www. bruker.com/products/mass-spectrometry-and-separations/maldi-toftof/microflex/overview.html (accessed on 16 September 2019). 
32. BD PhoenixTM M50 Instrument. Available online: https://www.bd.com/en-us/offerings/capabilities/microbiologysolutions/identification-and-susceptibility-testing/bd-phoenix-automated-identification-and-susceptibility-testing-system/ bd-phoenix-m50-instrument (accessed on 16 September 2019).

33. Sensititre Antimicrobial Susceptibility Testing System-IT. Available online: https://www.thermofisher.com/uk/en/home/ clinical/clinical-microbiology/antimicrobial-susceptibility-testing/sensititre-antimicrobial-susceptibility-testing-system.html (accessed on 16 September 2019).

34. Clinical and Laboratory Standards Institute. Performance Standards for Antimicrobial Susceptibility Testing; 20-Third Informational Supplement; Document M100-S25; Springer: Wayne, PA, USA, 2015.

35. EUCASTBreakpointV_9.0. 2019. Available online: https://www.eucast.org/fileadmin/src/media/PDFs/EUCAST_files/ Breakpoint_tables/v_9.0_Breakpoint_Tables.pdf (accessed on 11 November 2019).

36. Acinetobacter baumannii: Methods and Protocols; Methods in Molecular Biology; Springer Protocol; Springer: New York, NY, USA, 2019.

37. Yang, S.J.; Kreiswirth, B.N.; Sakoulas, G.; Yeaman, M.R.; Xiong, Y.Q.; Sawa, A.; Bayer, A.S. Enhanced expression of dltABCD is associated with the development of daptomycin nonsusceptibility in a clinical endocarditis isolate of Staphylococcus aureus. J. Infect. Dis. 2009, 200, 1916-1920. [CrossRef] [PubMed]

38. Yang, S.J.; Nast, C.C.; Mishra, N.N.; Yeaman, M.R.; Fey, P.D.; Bayer, A.S. Cell wall thickening is not a universal accompaniment of the daptomycin nonsusceptibility phenotype in Staphylococcus aureus: Evidence for multiple resistance mechanisms. Antimicrob. Agents Chemother. 2010, 54, 3079-3085, PMCID: PMC2916340. [CrossRef] [PubMed]

39. Rezania, S.; Amirmozaffari, N.; Tabarraei, B.; Jeddi-Tehrani, M.; Zarei, O.; Alizadeh, R.; Masjedian, F.; Zarnani, A.H. Extraction, Purification and Characterization of Lipopolysaccharide from Escherichia coli and Salmonella typhi. Avicenna J. Med. Biotechnol. 2011, 3, 3-9.

40. Mezzatesta, M.L.; D’Andrea, M.M.; Migliavacca, R.; Giani, T.; Gona, F.; Nucleo, E.; Fugazza, G.; Pagani, L.; Rossolini, G.M.; Stefani, S. Epidemiological characterization and distribution of carbapenem-resistant Acinetobacter baumannii clinical isolates in Italy. Clin. Microbiol. Infect. 2012, 18, 160-166. [CrossRef]

41. Tenover, F.C.; Arbeit, R.D.; Goering, R.V.; Mickelsen, P.A.; Murray, B.E.; Persing, D.H.; Swaminathan, B. Interpreting chromosomal DNA restriction patterns produced by pulsed-field gel electrophoresis: Criteria for bacterial strain typing. J. Clin. Microbiol. 1995, 33, 2233-2239. [CrossRef]

42. Towner, K.J.; Levi, K.; Vlassiadi, M.; ARPAC Steering Group. Genetic diversity of carbapenem-resistant isolates of Acinetobacter baumannii in Europe. Clin. Microbiol. Infect. 2008, 14, 161-167. [CrossRef] [PubMed]

43. McCracken, M.; Mataseje, L.F.; Loo, V.; Walkty, A.; Adam, H.J.; Hoban, D.J.; Zhanel, G.G.; Mulvey, M.R.; Canadian Antimicrobial Resistance Alliance (CARA). Characterization of Acinetobacter baumannii and meropenem-resistant Pseudomonas aeruginosa in Canada: Results of the CANWARD 2007-2009 study. Diagn Microbiol. Infect. Dis. 2011, 69, 335-341. [CrossRef]

44. Zankari, E.; Hasman, H.; Cosentino, S.; Vestergaard, M.; Rasmussen, S.; Lund, O.; Aarestrup, F.M.; Larsen, M.V. Identification of acquired antimicrobial resistance genes. J. Antimicrob. Chemother. 2012, 67, 2640-2644. [CrossRef] [PubMed]

45. Larsen, M.V.; Cosentino, S.; Rasmussen, S.; Friis, C.; Hasman, H.; Marvig, R.L.; Jelsbak, L.; Sicheritz-Pontén, T.; Ussery, D.W.; Aarestrup, F.M.; et al. Multilocus sequence typing of total-genome-sequenced bacteria. J. Clin. Microbiol. 2012, 50, $1355-1361$. [CrossRef] [PubMed]

46. Johansson, M.H.K.; Bortolaia, V.; Tansirichaiya, S.; Aarestrup, F.M.; Roberts, A.P.; Petersen, T.N. Detection of mobile genetic elements associated with antibiotic resistance in Salmonella enterica using a newly developed web tool: Mobile Element Finder. J. Antimicrob. Chemother. 2021, 76, 101-109. [CrossRef]

47. Zhou, Y.; Liang, Y.; Lynch, K.H.; Dennis, J.J.; Wishart, D.S. PHAST: A Fast Phage Search Tool. Nucleic Acids Res. 2011, 39, W347-W352. [CrossRef] [PubMed]

48. Pourcel, C.; Touchon, M.; Villeriot, N.; Vernadet, J.P.; Couvin, D.; Toffano-Nioche, C.; Vergnaud, G. CRISPRCasdb a successor of CRISPRdb containing CRISPR arrays and cas genes from complete genome sequences, and tools to download and query lists of repeats and spacers. Nucleic Acids Res. 2020, 48, D535-D544. [CrossRef] [PubMed]

49. Wick, R.R.; Heinz, E.; Holt, K.E.; Wyres, K.L. Kaptive Web: User-friendly capsule and lipopolysaccharide serotype prediction for Klebsiella genomes. J. Clin. Microbiol. 2018, 56, e00197-18. [CrossRef] [PubMed]

50. Wyres, K.L.; Cahill, S.M.; Holt, K.E.; Hall, R.M.; Kenyon, J.J. Identification of Acinetobacter baumannii loci for capsular polysaccharide $(\mathrm{KL})$ and lipooligosaccharide outer core $(\mathrm{OCL})$ synthesis in genome assemblies using curated reference databases compatible with Kaptive. Microbial. Genom. 2020, 6, e000339. [CrossRef] [PubMed]

51. Cingolani, P.; Platts, A.; Wang, L.L.; Coon, M.; Nguyen, T.; Wang, L.; Land, S.J.; Lu, X.; Ruden, D.M. A program for annotating and predicting the effects of single nucleotide polymorphisms, SnpEff: SNPs in the genome of Drosophila melanogaster strain w1118; iso-2; iso-3. Fly 2012, 6, 80-92. [CrossRef] [PubMed]

52. Cafiso, V.; Stracquadanio, S.; Lo Verde, F.; De Guidi, I.; Zega, A.; Pigola, G.; Stefani, S. Genomic and Long-Term Transcriptomic Imprints Related to the Daptomycin Mechanism of Action Occurring in Daptomycin- and Methicillin-Resistant Staphylococcus aureus Under Daptomycin Exposure. Front. Microbiol. 2020, 11, 1893. [CrossRef] [PubMed] 